\title{
Hepatitis A Virus
}

National Cancer Institute

\section{Source}

National Cancer Institute. Hepatitis A Virus. NCI Thesaurus. Code C14325.

A single stranded RNA virus. A member of the picornaviridae family, subfamily hepatovirus. The causative agent of Hepatitis A. 